\title{
A REVIEW ON THIN WALLED CRYOGENIC MACHINING ON INCONEL OR AEROSPACE MATERIALS
}

\author{
Budiman A.Y. ${ }^{1}$, Mohruni A.S. ${ }^{1 *}$ \\ ${ }^{1}$ Mechanical Engineering Department, Sriwijaya University, South Sumatera, Indonesia
}

\begin{abstract}
Cutting fluids are widely used in machining processes throughout the world. However, this cutting liquid is the source of many environmental pollution problems. In order to reduce or eliminate the effect produced by cutting fluids, it is necessary to switch to a continuous machining technique such as using small amounts of cutting fluid, liquid nitrogen, vegetable oil or compressed air as a cooling lubrication medium. Cryogenic coolant is found to be more efficient, economical, cost-effective and environmentally friendly when compared to the conventional coolant, especially in mass production. In machining difficult-to-cut materials such as thin walled materials for the aerospace industry, cooling applications are needed. Ni-based super alloy, Inconel is a material for aerospace applications because of its high durability to wear and material that is resistant to oxidation and corrosion at high temperatures. This paper presents a review and explanation of thin wall machining using cryogenic cooling systems on Inconel or aerospace materials.
\end{abstract}

Keywords: Cryogenic, Thin Walled, Inconel.

\section{INTRODUCTION}

Thin-walled parts have been widely used in increasing the number of applications in various industrial sectors, such as the aviation, aerospace and automotive industries [1][2][3].

Inconel, Ni-based superalloys is material for aerospace applications because of high wear resistance and materials that are resistant to corrosion and oxidation at high temperatures [4].

Conventional liquids and lubricants are widely used in machining processes throughout the world. However, this cutting liquid is the source of many environmental pollution problems. In order to reduce or eliminate the effect produced by cutting fluids, it is necessary to switch to a continuous machining technique such as using small amounts of cutting fluid, liquid nitrogen, vegetable oil or compressed air as a cooling lubrication medium. Liquids used in sustainable machining methods are considered truly biodegradable and environmentally friendly [5].

\section{CRYOGENIC MACHINING}

Cryogenic process is defined as a sustainable cooling process in a conventional heat treatment cycle. The benefits of this cryogenic process have been known for centuries [6].

Table 1. Various cooling and lubricating strategies for effectiveness and application [6]

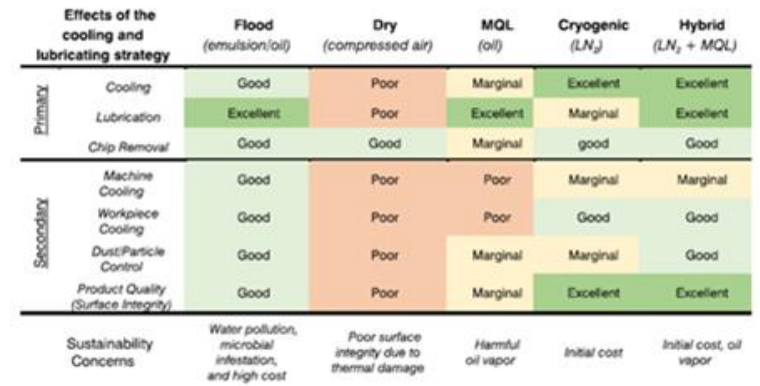

Cryogenic cooling techniques are known to be more efficient, economical, cost-effective and environmentally friendly when compared to conventional refrigeration, especially in mass production [7].

Kaynak and Gharibi [7] studied various cooling strategies and lubricant-assisted cooling strategies to improve machining performance in the AISI 4140 steel turning process. Liquid nitrogen $\left(\mathrm{LN}_{2}\right)$ and carbon dioxide $\left(\mathrm{CO}_{2}\right)$ were used as cryogenic coolants, and the performance of these coolants was compared to see tool wear. The results of cryogenic machining using liquid

*Corresponding author's email: mohrunias@unsri.ac.id 
nitrogen show reduced tool wear, including base and nose wear, in the machining process of AISI 4140 steel material. They also showed that carbon dioxide-assisted cryogenic machining helps to increase chip breakability.

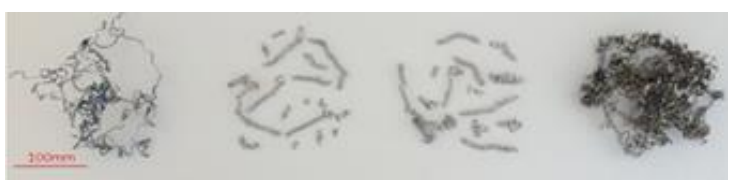

Figure 1. Images of generated chips under dry, carbon dioxide $\left(\mathrm{CO}_{2}\right), \mathrm{CO}_{2}+\mathrm{MQL}$, and liquid nitrogen $\left(\mathrm{LN}_{2}\right)$-assisted machining conditions [7].

Shokrani and Newman [8] investigated the cryogenic end milling machining of Ti-6Al-4V in various cutting tool geometries. Their investigation showed that the angle of 14 rakes and 10 primary clearance is the geometry that is most suitable for cryogenic machining. They also studied the effect of cutting speed on tool life and the results showed that a cutting speed of 110 $\mathrm{m} / \mathrm{min}$ the longest tool life and allowed an increase in productivity up to $83 \%$ when machining Ti-6Al-4V. Overall the results show a significant impact on the performance of Ti-6Al$4 \mathrm{~V}$ machining with a much higher material removal rate.

Traditional cutting fluids are replaced by liquid nitrogen $\left(\mathrm{LN}_{2}\right)$ or carbon dioxide $\left(\mathrm{CO}_{2}\right)$ which must be injected in the cutting zone during cryogenic removal. The $\mathrm{CO}_{2}$ used in cryogenic machining is no longer used and will be depleted into the atmosphere. Thus, the harmless environment associated with cryogenic machining is maintained. The comparison between $\mathrm{LN}_{2}$ and $\mathrm{CO}_{2}$ can be seen in Table 2 [9]

Table 2. $\mathrm{LN}_{2}$ and $\mathrm{CO}_{2}$ comparison [9]

\begin{tabular}{|c|c|c|}
\hline & Advantages & Disaciantages \\
\hline \multirow{3}{*}{$\begin{array}{l}\text { Liquid nitrogen } \\
\left(\mathrm{LN}_{2}\right)\end{array}$} & Higher cooling capacity $\left(-196^{\circ} \mathrm{C}\right)$ & A bit more expensive than $\mathrm{CO}_{2}$ \\
\hline & $\begin{array}{l}\text { No exhaust systems are needed } \\
\text { inside machine-tools }\end{array}$ & $\begin{array}{l}\text { Storage at low temperature } \\
\text { imvolves leakages by boiling }\end{array}$ \\
\hline & Lubricant properties & $\begin{array}{l}\text { Higher expansion rate } \\
(\approx 700 \text { times) }\end{array}$ \\
\hline \multirow[t]{3}{*}{$\begin{array}{l}\text { Liquid carbon } \\
\text { dioxide }\left(\mathrm{CO}_{2}\right)\end{array}$} & $\begin{array}{l}\text { Pressurised bottles ( } 60 \text { bar) at } \\
20-25^{\circ} \mathrm{C} \text { without loss by boiling }\end{array}$ & Lower cooling capacity $\left(-78^{\circ} \mathrm{C}\right)$ \\
\hline & A bit cheaper than $\mathrm{LN}_{2}$ & Hannful in high concentrations \\
\hline & Dissolves oil in supercritical state & $\begin{array}{l}\text { If output pressure is not } \\
\text { controlled, dry ice can be } \\
\text { formed }\end{array}$ \\
\hline
\end{tabular}

Pereira and Delijaicov investigation evaluate the influence of the cutting parameters on the surface integrity of Inconel 718 turned under cryogenic conditions using liquid nitrogen $\left(\mathrm{LN}_{2}\right)$ at high cutting speeds and the results showed that lower cutting parameters tend to give the best results in terms of the cutting force and surface integrity [10].

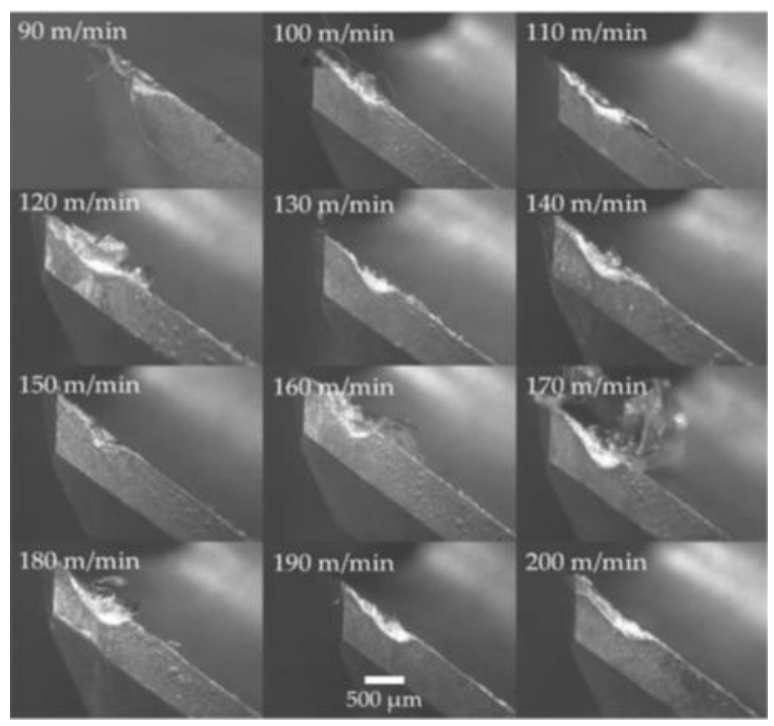

Figure 2. Micrographs of cutting tool wear after machining experiments showing the flank face of the cutting tool [8]

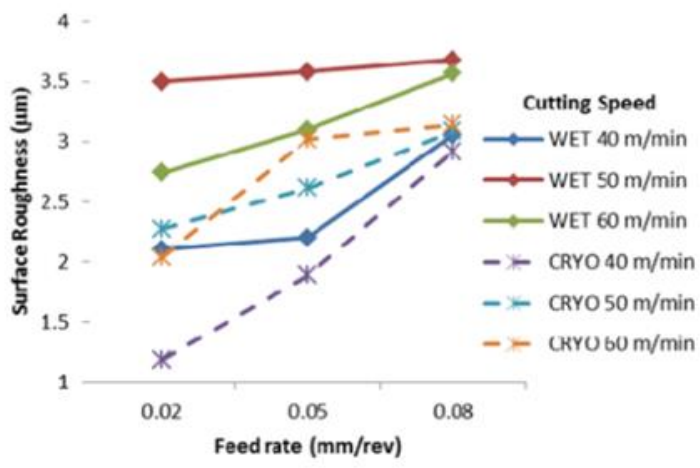

Figure 3. Surface roughness vs. feed rate [11].

Ahmed and Kumar [11] reported effects of cryogenic liquid nitrogen $\left(\mathrm{LN}_{2}\right)$ coolant during drilling of Ti-6Al-4V alloy material with three different levels of cutting speed $\left(\mathrm{V}_{\mathrm{c}}\right)$ and feed rate (f) at a constant depth. Cutting temperature (T), thrust force $\left(\mathrm{F}_{\mathrm{z}}\right)$, torque $\left(\mathrm{M}_{\mathrm{z}}\right)$, surface roughness $(\mathrm{Ra})$, and hole quality are the output responses investigated by using cryogenic $\mathrm{LN}_{2}$ coolant compared with a wet coolant. Tool wear and chip morphology were examined with the changes in cryogenic $\mathrm{LN}_{2}$ coolant. They found that the cryogenic $\mathrm{LN}_{2}$ coolant produced a reduction in the temperature of the cutting zone which helped to eliminate more heat from the cutting zone. In the condition of cryogenic $\mathrm{LN}_{2}$ they find lower thrust and smoother surface roughness due to less friction and better chip breaking. Better chipping also results in improved quality of hole under cryogenic $\mathrm{LN}_{2}$ conditions. The main use of 
cryogenic $\mathrm{LN}_{2}$ coolant in the cutting zone provides better and more effective lubrication than wet coolant. This shows that the cryogenic $\mathrm{LN}_{2}$ cooler is a substitute choice for wet coolers in the drilling machining.

\section{THIN WALLED MACHINING}

Thin-walled structures are used in the aerospace and automotive industries. They have an excellent structural homogeneity and an excellent strength to weight ratio. In thin-wall machining, the thickness of the wall decreases gradually during cutting, this makes this process a very complicated process [12].

Bolar and Joshi [13] studied a realistic threedimensional, thermo-structural, finite-elementbased mathematical model for thin-wall milling of aluminum alloy for aerospace materials. They simulate the interaction between helical milling cutter and the workpiece with explicit solution lagrangian formulation scheme. They found that the developed three dimensional mathematical model provided very useful insights into the complex physical interaction of helical cutting tool and workpiece during thin-wall milling of aerospace alloys.

Borojevic, et al., [14] Investigated the manufacturing and optimization of thin-walled aluminium alloy components for milling process. In their research a methodology for optimization of milling parameters was developed and presented. They analyzed the influence of tool trajectory strategies, wall thickness and feed rate, deviation of dimensional accuracy, deviation of shape and position accuracy, and surface roughness in thin-walled machining. Their results indicate an appropriate empirical model of response and the optimization of results is carried out using the response surface methodology. Verification of the optimization results is carried out using two additional experiments and shows a satisfying match with the calculated optimal value.

Isaev, et al. [15] Investigated of structure, properties and machinability rate of raw and thermal treated titanium alloys powder material used to produce the thin-walled components using electron beam melting $(\mathrm{EBM})$. The quality of the final product in terms of geometrical tolerance and stability of thin wall thicknesses was also included in their study. The specially designed measurement information system were used to take into account when selecting cutting conditions by controlling vibration during the machining process. This is because milling of thin-walled parts produced by EBM technology, shape accuracy and surface roughness are functions of variable wall stiffness that is estimated in the local cutting zone.

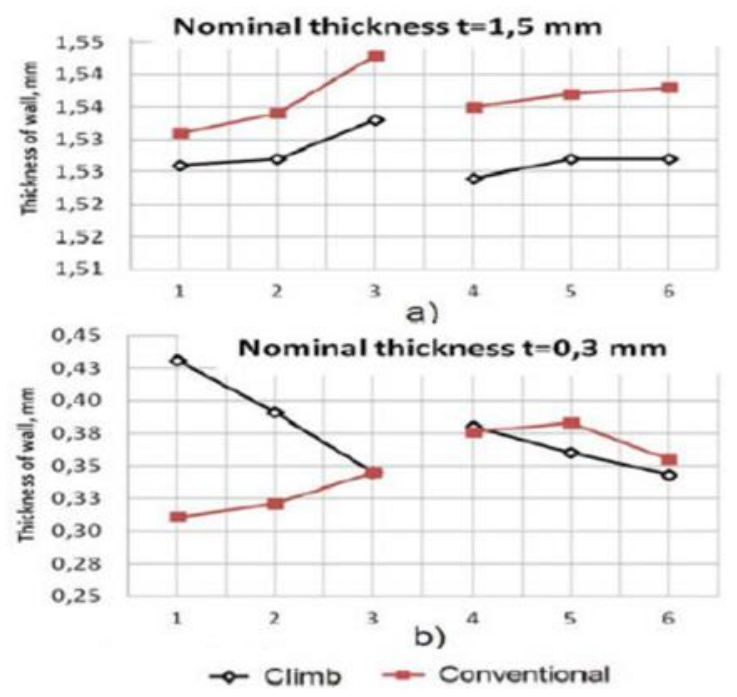

Figure 6. Walls thickness variations depending on the measuring point and milling type: (a) for nominal wall's thickness of $1.5 \mathrm{~mm}$; (b) for nominal wall's thickness of $0.3 \mathrm{~mm}$ [15].

\section{CRYOGENIC MACHINING ON INCONEL OR AEROSPACE MATERIALS}

Ni-based super alloys were made in the 1940s primarily in gas turbine applications because of their strength and toughness at high temperatures and higher creep resistance properties than available steel materials. Machining of aerospace material has developed in recent years although the characteristics of alloys such as titanium or nickel-based alloys cause high cutting forces, rapid tool wear, and excessive heat [16][17].

Cryogenic cooling systems can be used for machining materials that are difficult to cut such as Inconel 718 and some researchers have conducted research in this way [18][19][20][21].

The optimization of the final milling operation parameters for Inconel 718 super alloy was investigated by Maiyar, et al [22] with multiresponse criteria based on orthogonal taguchi arrangements with gray relational analysis. To identify the most significant factors, analysis of variance (ANOVA) was applied. The results of the experiments and the developed models have been compared and the experimental results show that machining performance in the end milling 
process can be effectively improved by this method approach.

\section{CONCLUSION}

Cryogenic cooling in metal cutting has long been studied, however, many studies and the most extraordinary of them especially in terms of application methods have been carried out in the last decade and surprising results have been achieved.

Cryogenic cooling is still interesting to be examined more deeply, especially for difficult to cut material. Inconel is a Ni-based super alloy material for aerospace applications because of its excellent mechanical and thermal properties along with high resistance to corrosion and fatigue at high temperatures. However, it is a difficult-to-cut material owing to its high strength.

The machining of thin-walled aerospace parts is difficult to realize high efficiency and precision. It is very challenging to choose the optimal machining process under limited technological conditions.

There are a large number of factors that affect the quality and efficiency of thin-walled aerospace machinery, specifically the cooling system and process parameters. Machining technologies such as cryogenic cooling are specifically designed to minimize heat generated on the surface between the tool and the workpiece and also the tool and the chip. This development ensures that the tool material retains its properties to ensure that more efficient and economical machining of inconel or aerospace materials can be achieved.

\section{REFERENCES}

[1] X. Jiang, W. Lu, and Z. Zhang, "An Approach for Improving the Machining Efficiency and Quality of Aerospace Curved Thin-Walled Parts during Five-Axis NC Machining," Int. J. Adv. Manuf. Technol., vol. 97, no. 5-8, pp. 2477-2488, 2018, doi: 10.1007/s00170-018-2129-0.

[2] L. Jiang et al., "Research on Bending Forming Method of Large DiameterThickness Ratio Thin-Walled Tubes for Aerospace," Int. J. Adv. Manuf. Technol., vol. 102, no. 9-12, pp. 3037-3049, 2019, doi: 10.1007/s00170-019-03328-7.

[3] J. SHI, Q. SONG, Z. LIU, and X. AI, "A Novel Stability Prediction Approach for
Thin-Walled Component Milling Considering Material Removing Process," Chinese J. Aeronaut., vol. 30, no. 5, pp. 1789-1798, 2017, doi: 10.1016/j.cja.2017.05.011.

[4] A. U. H. Mohsan, Z. Liu, and G. K. Padhy, "A Review on the Progress towards Improvement in Surface Integrity of Inconel 718 under High Pressure and Flood Cooling Conditions," Int. J. Adv. Manuf. Technol., vol. 91, no. 1-4, pp. 107-125, 2017, doi: 10.1007/s00170-016-9737-3.

[5] Chetan, S. Ghosh, and P. Venkateswara Rao, "Application of Sustainable Techniques in Metal Cutting for Enhanced Machinability: A Review," J. Clean. Prod., vol. 100, no. March, pp. 17-34, 2015, doi: 10.1016/j.jclepro.2015.03.039.

[6] I. S. Jawahir et al., "Cryogenic Manufacturing Processes," CIRP Ann. Manuf. Technol., vol. 65, no. 2, pp. 713-736, 2016, doi: 10.1016/j.cirp.2016.06.007.

[7] Y. Kaynak and A. Gharibi, "Progressive Tool Wear in Cryogenic Machining: The Effect of Liquid Nitrogen and Carbon Dioxide," $J$. Manuf. Mater. Process., vol. 2, no. 2, p. 31, 2018, doi: 10.3390/jmmp2020031.

[8] A. Shokrani and S. T. Newman, "A New Cutting Tool Design for Cryogenic Machining of Ti-6Al-4V Titanium Alloy," Materials (Basel)., vol. 12, no. 3, pp. 1-14, 2019, doi: 10.3390/ma12030477.

[9] O. Pereira, A. Rodríguez, J. Barreiro, A. I. Fernández-Abia, and L. N. L. de Lacalle, "Nozzle Design for Combined Use of MQL and Cryogenic Gas in Machining," Int. J. Precis. Eng. Manuf. - Green Technol., vol. 4, no. 1, pp. 87-95, 2017, doi: 10.1007/s40684017-0012-3.

[10] W. H. Pereira and S. Delijaicov, "Surface Integrity of INCONEL 718 Turned under Cryogenic Conditions at High Cutting Speeds," Int. J. Adv. Manuf. Technol., pp. 2163-2177, 2019, doi: 10.1007/s00170-01903946-1.

[11] L. S. Ahmed and M. P. Kumar, "Cryogenic Drilling of Ti-6Al-4V Alloy Under Liquid Nitrogen Cooling," Mater. Manuf. Process., vol. 31, no. September, pp. 951-959, 2015, doi: 10.1080/10426914.2015.1048475. 
[12] B. V. Ramanaiah, B. Manikanta, M. Ravi Sankar, M. Malhotra, and K. Gajrani, "Experimental Study of Deflection and Surface Roughness in Thin Wall Machining of Aluminum Alloy," Mater. Today Proc., vol. 5, no. 2, pp. 3745-3754, 2018, doi: 10.1016/j.matpr.2017.11.627.

[13] G. Bolar and S. N. Joshi, "ThreeDimensional Numerical Modeling, Simulation and Experimental Validation of Milling of a Thin-Wall Component," Proc. Inst. Mech. Eng. Part B J. Eng. Manuf., vol. 231, no. 5, pp. 792-804, 2017, doi: $10.1177 / 0954405416685387$.

[14] S. Borojevic, D. Lukic, M. Miloševic, J. Vukman, and D. Kramar, "Optimization of Process Parameters for Machining of $\mathrm{Al}$ 7075 Thin-Walled Structures," Adv. Prod. Eng. Manag., vol. 13, no. 2, pp. 125-135, 2018, doi: 10.14743/apem2018.2.278.

[15] A. Isaev, V. Grechishnikov, P. Pivkin, K. Mihail, Y. Ilyuhin, and A. Vorotnikov, "Machining of Thin-Walled Parts Produced by Additive Manufacturing Technologies," Procedia CIRP, vol. 41, pp. 1023-1026, 2016, doi: 10.1016/j.procir.2015.08.088.

[16] E. O. Ezugwu, "Key Improvements in the Machining of Difficult-to-Cut Aerospace Superalloys," Int. J. Mach. Tools Manuf., vol. 45, no. 12-13, pp. 1353-1367, 2005, doi: 10.1016/j.ijmachtools.2005.02.003.

[17] D. Umbrello, "Investigation of Surface Integrity in Dry Machining of Inconel 718," Int. J. Adv. Manuf. Technol., vol. 69, no. 912, pp. 2183-2190, 2013, doi: 10.1007/s00170-013-5198-0.
[18] F. Pusavec, H. Hamdi, J. Kopac, and I. S. Jawahir, "Surface Integrity in Cryogenic Machining of Nickel Based Alloy - Inconel 718," J. Mater. Process. Technol., vol. 211, no. 4, pp. 773-783, 2011, doi: 10.1016/j.jmatprotec.2010.12.013.

[19] D. A. Stephenson, S. J. Skerlos, A. S. King, and S. D. Supekar, "Rough Turning Inconel 750 with Supercritical CO2-Based Minimum Quantity Lubrication," J. Mater. Process. Technol., vol. 214, no. 3, pp. 673-680, 2014, doi: 10.1016/j.jmatprotec.2013.10.003.

[20] F. Pusavec et al., "Sustainable Machining of High Temperature Nickel Alloy - Inconel 718: Part 1 - Predictive Performance Models," J. Clean. Prod., vol. 81, pp. 255269, 2014, doi: 10.1016/j.jclepro.2014.06.040.

[21] F. Pusavec et al., "Sustainable Machining of High Temperature Nickel Alloy - Inconel 718: Part 2 - Chip Breakability and Optimization," J. Clean. Prod., vol. 87, no. 1, pp. 941-952, 2015, doi: 10.1016/j.jclepro.2014.10.085.

[22] L. M. Maiyar, R. Ramanujam, K. Venkatesan, and J. Jerald, "Optimization of Machining Parameters for End Milling of Inconel 718 Super Alloy Using Taguchi Based Grey Relational Analysis," Procedia Eng., vol. 64, pp. 1276-1282, 2013, doi: 10.1016/j.proeng.2013.09.208. 